\title{
Nonverbal Communication Reconstruction on Facebook
}

\author{
Yuli Candrasari \\ ORCID iD: 0000-0001-5534-6285, Universitas Pembangunan Nasional "Veteran” Jawa \\ Timur, J1. Raya Rungkut Madya, Gunung Anyar, Surabaya, East Java 60294, Indonesia \\ *Corresponding author, e-mail: yuli_candrasari.ilkom@upnjatim.ac.id
}

\begin{abstract}
Facebook provides users comfort in communicating even though they cannot see expressions or any other nonverbal signs, which have been an essential factor in supporting faceto-face communication. Therefore, this research is necessary because the absence of nonverbal communication, especially facial expression, touching, and gesture, renders the communication process between individuals ineffective and uncomfortable, as it was when people first used email to communicate via the internet. Through the study of Computer-Mediated Communication (CMC) perspectives, nonverbal communication, Social Presence Theory and Lack of Social Context Cues theory, this paper will discuss forms of nonverbal communication in the digital era. This study is based on research conducted by researchers using the netnography method and carried out through literature studies. The research was conducted on the Muslim community Bening Society on Facebook because the communication between them is very intense, as required in netnography. The loss of nonverbal communication in interpersonal communication does not, in fact, reduce netizens' comfort in communicating and interacting. The emergence of digital emoticons and nonverbals is a substitute for nonverbal communication because digital emoticon and nonverbal functions in mediated interpersonal communication are the same as nonverbal communication.
\end{abstract}

Keywords: Computer-Mediated Communication, Nonverbal Communication, Emoticon, Muslim Community, Facebook.

\section{Introduction}

Facebook has many opportunities for users to interact directly with other individuals (Kasanah, 2011); it can also be a vehicle for building committed, romantic relationship, and interdependent relationships (Craig, Elizabeth \& Wright, B., 2012; Stieger et al., 2013). The individual motive to use Facebook is to do interpersonal communication and express themselves (Adnan \& Mavi, 2015; Hunt et al., 2012). Individuals do this because they feel social media has met individuals' needs to interact and communicate with the social environment--as human nature as social beings who always want to be connected and share with other parties. But social media mediated communication has disadvantages when compared to face-to-face communication. One of them is the loss of the social cues that are an essential part of interpersonal communication.

One of the fundamental differences is the loss of some symbols or nonverbal language. In internet-mediated touch, facial expressions, body movements, voice intonation, and performance will be challenging to obtain. In the process of interpersonal communication, these nonverbal symbols have a significant role. If words alone are used as verbal language in interpersonal communication, it won't be easy to give meaning to messages that are only words. Nonverbal language support is needed to define spoken language--the role of language or nonverbal symbols that play a role in smoothing the communication process bearing in mind that the truth in communication depends not only on what is said but is very dependent on how the message is delivered. As stated by

Article History: Received October 31, 2019; Revised July 07, 2020; Accepted February 19, 2021; Published November 01, 2021 
Burgoon, Buller, and Woodall, nonverbal cues will more easily influence the recipient's perception than verbal cues. In face-to-face communication, nonverbal cues such as eye contact, gaze, tone of voice, and gesture can be a trusted factor for communication to assess the communicator's personality, abilities, and sexual orientation (Burgoon et al., 1996). The loss of nonverbal cues in the Computer-Mediated Communication (CMC) may result in ambiguous communication.

As stated by Burgoon (in Konijn et al., 2008) nonverbal cues will more easily influence the recipient's perception than verbal cues. Up to $60-65 \%$ of social meaning comes from nonverbal behavior. (Remland, 2017) mentioned that nonverbal has the main function for identity disclosure, status display, emotional exchange, and delivery of verbal messages in the interpersonal communication process.

The loss of nonverbal cues in mediated communication (internet) may result in ambiguous touch. This condition is inversely proportional to the communication process via the internet. In interpersonal communication carried out in cyberspace, individuals no longer get nonverbal communication as in face-to-face interpersonal communication. Facial expressions are a meaningful source of information in face-to-face communication (Aldunate \& González-Ibáñez, 2017). To replace the loss of nonverbal symbols in the communication process on social media, including Facebook, certain characters are created known as emoticons. Emoticons are paralinguistic cues that help internet users to interpret communication in text form. Emoticons are indicators of emotion in Facebook user posts (Marengo et al., 2017; Tov, 2015). These emoticon symbols are then 'agreed upon' by internet users to be used as a substitute for nonverbal signs that usually appear in face-to-face communication processes. Forms of a close relationship constructed with nonverbal symbols such as touch, facial expressions are replaced or simplified with emoticons on the internet.

In fact, in mediated interpersonal communication, participants cannot find nonverbal cues such as face-to-face communication, but they can communicate face-toface communication. This phenomenon is easy to find for Facebook users, including communities that exist on Facebook. Most of the community members who are on Facebook initially do not know each other, and even many have never met physically. The fact is that members of the community can communicate well as if they have known each other before, even though, in the process of communicating through the Facebook wall, they never find nonverbal communication, such as expressions, appearances, intonations, such cues being indispensable in the process of face-to-face interpersonal communication. In face-to-face communication, nonverbal communication becomes essential to judge other people, especially new people.

This phenomenon occurs in one of the Facebook communities, namely the Bening Society, which is a community of Muslim women. The community members initially did not know each other; they joined the Bening Society community because of the relationship between the seller and the consumer, but the interaction and communication between members of the community were good enough so that emotional closeness was built between the members who were always increasing in number. They even created distinctive symbols and designations known only to members of the Bening Society community. This study will examine how nonverbal cues, especially facial expressions, touch, and gestures, in mediated interpersonal communication seem to change a lot of nonverbal cues that have been studied in face-to-face interpersonal communication. This study not only examines how many nonverbals are replaced with text or symbols but also 
explores how community members interpret the functions of symbols based on the values and culture of the community.

Social networking sites have provided easier access for users to build social relationships (Pearce et al., 2015) and also increase the frequency of communication with other individuals (Stafford \& Hillyer, 2012). There has been a rapid increase in the number of users of social networking sites because these sites provide cheaper 'costs' (Ellison et al., 2014) for individuals who want to build social relationships and communicate with other individuals compared with face-to-face communication.

The desire to connect with other people in society can motivate online users to participate in social networking sites. Individuals also choose to maintain relationships through social media based on positive experiences and the comfort they have felt while using social media. Amichai-Hamburger and Vinitzky state that the internet has created a comprehensive and safe environment for individuals to express themselves or communicate effectively (Amichai-Hamburger \& Vinitzky, 2010). Such phenomena also appear on social media, which is a new form of communication and human interaction (Mulyadi \& Fitriana, 2018), and social media are replacing old ways of communicating (Indriani \& Prasanti, 2019), including the social networking sites. It is undeniable that social networking sites have become a favorite for internet users when surfing in cyberspace. This is because social media can deliver messages quickly, reach many people and have facilities that support communication with other individuals (Veil et al., 2011). This can be seen by netizens using social networking sites every day for 4-8 hours or more (Sait \& Sattar, 2018).

These emoticons later became a new form of culture in cyber society, namely emoticons as a global language. This symbol has been accepted with the same meaning by all internet users even though they come from different regions or countries. A phenomenon like this then attracts researchers' attention that the internet has made a local culture or individual culture 'lost' and replaced with internet/global culture. An example is how the laughter symbol becomes the same among all countries. It is well-known that laughter in different regions will have differences.

As explained in the perspective of cues-filtered-out, it is said that, in CMC, there is no face-to-face, so the emotional context is reduced, and other nonverbal communication cues such as voice, appearance, gestures, or facial expressions are difficult to find (Walther, 1996). As a result, mediated communication is considered to be less effective and is seen as not good enough to build a relationship. This is due to the absence of touch and eye gaze so that, in mediated communication, it is challenging to produce intimate relationships. In personal face-to-face communication, nonverbal cues are essential compared to verbal cues. Nonverbal cues give meaningful emphasis to meaning in verbal cues. Nonverbal cues are a form of emotional representation or feelings of individuals involved in communication. When mediated communication is performed, many nonverbal cues are lost or not seen by individuals involved.

To overcome this situation, netizens have found a way to make social life online, seeking to create several ways to use text-based interpersonal communication. As stated by Walther and D'Addario, among others are interpreting written language well, asking questions if they have not understood the message, using self-disclosure, paying attention to chronemic cues (repetitive patterns) and using emoticons (in Riordan, 2011). Of these methods, the most popular among social media users in 'overcoming' the loss of nonverbal cues is to use emoticons. Emoticons are widely used in CMC as a form of 
compensation for the loss of nonverbal symbols and offset the absence of nonverbal cues in written communication (Thompson \& Filik, 2016). Emoticons are often used as a medium to express feelings on instant messages (Urabe et al., 2013), reinforce verbal messages (Hwang, 2014), mark a positive attitude, a joke (Skovholt et al., 2014), and in clarifying messages (Thompson \& Filik, 2016). Emoticons have various forms and meanings, most of which are facial expressions. In one CMC study, text messages accompanied by emoticons proved to have a positive impact on emotional responses (Thompson et al., 2016).

Signs that are attached to these emoticons are from Western culture and are used in the context of Western culture (Dresner \& Herring, 2010). In CMC, many internet users use emoticons. Especially female users. The results of Wolf's (2000) research stated that, compared to men, women used emoticons more in conducting social media mediated communication (Bickell, 2014; Huffaker \& Calvert, 2017). Emoticons are used by individuals to show their self-image and can make an impression (Krishnan, 2019) when interacting in cyberspace (Tseng \& Hsieh, 2017).

Emoticons are created in the form of symbols that can represent the emotional state or feeling of CMC users. Emoticons are often used to communicate in cyberspace to overcome the loss of nonverbal communication in CMC (Hogenboom et al., 2013). The results of emoticon research say that netizens, when communicating in $\mathrm{CMC}$, express their feelings not only with words but also concise symbols (emoticons) (Fischer, 2011). Emoticons will often be used when individuals understand the meaning of these emoticons (Liu et al., 2018) because emoticons can easily be a strong indicator of a positive impression (Huynh et al., 2013) in a communication on social media where the individuals involved do not see each other nonverbal cues make it able to judge other individuals as in face-to-face communication.

In contrast to previous studies that have looked at the effects of using emoticons in instant messages, this study explore the nonverbal construction of Facebook users, especially in the Bening Society women's community and their interpretation based on the values and culture of the community. An interesting phenomenon for researchers because Facebook as a social media does not have the character of an instant messages.

Emoticons, derived from emotion and iconic words, are currently widely used in social media, especially in the socio-emotional context. As the third research objective, researchers will examine how the symbols used in the process of interpersonal communication become simpler with the use of emoticons. As explained above, some nonverbal symbols will be lost or cannot be found in the internet-mediated communication process. Such as the tone of voice, gesture (body language), facial expression, and appearance will be difficult to obtain in the process. In order to support the verbal communication process in internet-mediated communication, certain symbols are used, one of which is an emoticon.

\section{Methods}

This research is qualitative research using the netnography method. Netnographic research is a study that examines communities in cyberspace. According to Kozinets (Kozinets, 2015), as the initiator of the netnography method, online communities will shape and embody the values, customs, and beliefs that govern and direct the behavior of the community. In short, although netizens' social interactions and relationships are computer-mediated, online communities form a particular culture. Netnography is simply a method for studying cybernetics space (cyberspace). Kozinets (Bowler \& Bowler Jr, 
2010) wrote about the superiority of netnography in studying social interactions online. As ethnography, netnography is natural, descriptive, multi-method, adaptive, and focused on its context. Using netnography, this research will examine how netizens can interact and communicate well even though nonverbal symbols are not seen as in face-to-face communication. If netizens then use certain characters such as emoticons, these symbols can replace nonverbal signs. This research was conducted on one of the Bening Society Facebook accounts. Researchers chose this community because it is active, meaning that community members have intense interaction and high conversation 'traffic' as required in netnography.

\section{Results}

This research was conducted by observing the Bening Society Facebook Community account for six months, mainly by observing messages that appeared on the Facebook account at any time, either in the form of status posts carried out by the account owner or manager and conversations which commented on the post. The Bening Society community account has not only a large number of followers but also a high frequency of posts that occur on the Facebook account. The Bening Society community account has been around since 2015. This community is one whose members are women of reproductive age and they initially joined because of the similarity of 'profession,' namely as an online business. Then it developed into a forum for young women of productive age to share information and experiences. The uniqueness of this community is that, although it is open, it does not have male members. Until now, this community has a membership of 6698 people (data accessed in 2020) and is active. In addition, this study also conducted in-depth interviews with nine active members of the Bening Society Facebook account.

The data of this study indicate that the informants, as members of the Bening Society community, claimed that at first, they did not know each other. Still, because they liked the Clear Hijab product, they settled into the Bening Society community. The exciting thing in this study is that members of the Bening Society community can interact and communicate well and comfortably even though they basically do not know each other and have never met physically. This means that communication between Bening Society community members can be appropriately interpreted even though there are no nonverbal symbols as in face-to-face communication; the use of nonverbal signs is the main thing. The message-meaning process can take place correctly. The absence of nonverbal symbols is replaced with certain characters in the form of text and logos. One of them is widely known and used emoticons.

Emoticons present in social media are intended to help social media users in expressing individual emotions or feelings. This was also revealed in this study. In the Bening Society, Bening members use a lot of emoticons to describe their feelings. Emoticons are widely used by members, especially when they respond to a post on the Bening Society's Facebook wall page. When observed from the Bening Society's Facebook page, emoticons are always used by Bening residents when the communication process takes place through Facebook, although not as much as verbal language. As in the process of face-to-face communication, the existence of nonverbal cues always follows verbal cues. But emoticons are used by Bening residents in the hope of representing feelings when words (verbal language) do not adequately express it. As stated by the following first informant who often uses emoticons. Likewise what was said 
by the admin of the Bening Society Facebook group that uses more emoticon symbols than 'slank' language in mediated interpersonal communication.

Frequent emoticons used in the posting on the Facebook Bening Society illustrate that emoticons are not just a picture or symbol but have been assessed by netizens as symbols that can represent the emotional condition of netizens, like the emoticons smiling, laughing, crying, and signs of love. In addition to emoticons that show facial expressions of members of the Bening Society community, they also often use thumb emoticons. This is in line with research conducted by Wolf (2000) that $30 \%$ of posts on the internet use emoticons, and Huffaker and Calvert found that some of the messages posted on teen websites contain emoticons (Huffaker \& Calvert, 2017).

Are Emoticons Replacing the Nonverbal Symbol Function?

The results of this study indicate that emoticons have several functions in the communication process carried out among members of the Bening Society community. First, the emoticon serves as a representation of feelings. If in face-to-face communication, feelings or emotions express nonverbal symbols in mediated interpersonal communication (internet), netizens use emoticons to describe their emotions. Observations on the Bening Society community Facebook account (Figure 1) show that all women members often describe that emoticons are used in posts and comments that appear in the account.

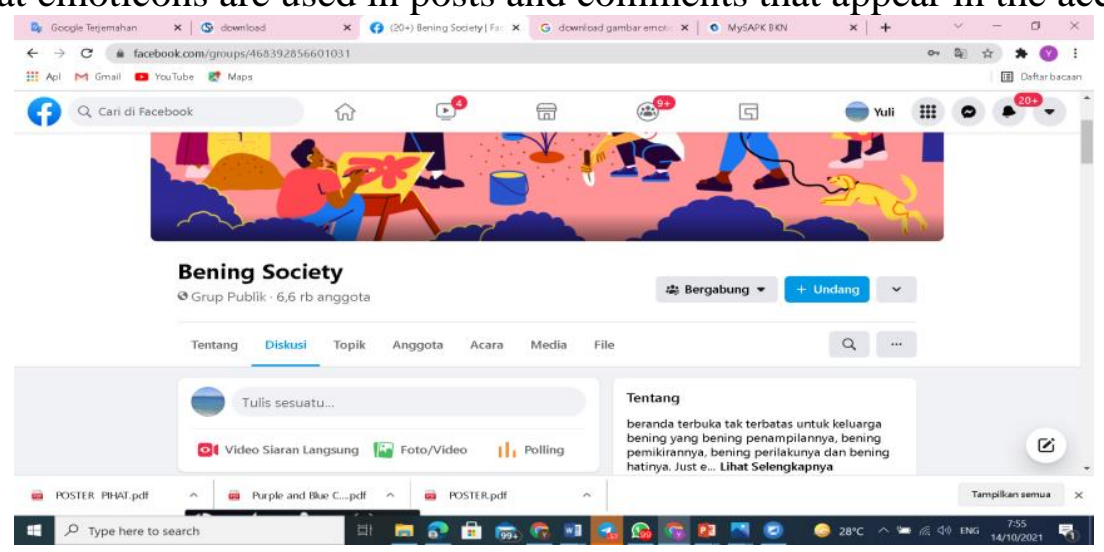

Figure 1. Bening Society Community Account on Facebook (source: facebook.com/groups/beningsociety/?ref=share)

Several studies of patterns of use of emoticons in short texts (SMS) show that women send messages containing emoticons more often than men (Hu et al., 2016). For women, it is not enough when expressing feelings only through written texts; it must be accompanied by symbols that can describe the condition of her feelings. As stated by the following first informant: "sometimes used to represent things that are funny and sad that cannot be expressed in words." The same thing was said by the eighth informant as follows: "ordinary emoticons for drawing something that is not enough to be written in a series of words."

Apart from these conditions, currently, emoticons have become a symbol that is accepted by netizens as a means to show the emotional condition and expression in the communication process. Emoticons have become nonverbal cues that are effective in completing verbal cues in mediated communication. It was proven that the Bening Society residents considered that emoticons were able to represent what they felt even though not all of their feelings could be conveyed only through the images available on emoticons. As stated by the following third informant: "Not bad ... with emoticons, I can say what I want to say. Although sometimes confused to find the right picture for the expression of what doesn't taste." 
The same thing was stated by the ninth informant who often uses emoticons to express her feelings. This fact shows that the use of emoticons is intended as a symbol that represents facial expressions that cannot be seen in the CMC. Emoticons are also used as a way for netizens to convey their feelings. A previous study states the use of emoticons to convey emotional expression as well as a way to maximize the recipient of the message in understanding the intent and emotional meaning of the message conveyed in textual form (Kaye et al., 2017).

In addition, the use of emoticons not only complements verbal messages but the use of emoticons is intended as a form to reinforce feelings. This is because, in every relationship between individuals, emotional involvement or feeling is needed for the comfort of the relationship. If in face-to-face communication emotional involvement or feelings can be captured directly by the five senses, then mediated communication can be expressed and seen through emoticons. The two statements also show that the informant's (netizen) motive of using emoticons is to provide information to the recipient about feeling happy and describing something funny. This is in line with the research conducted by Derks, Bos, and Von Grumbkow (Derks et al., 2008), which states that there are three individual reasons for using emoticons, namely to strengthen verbal messages, to express a sense of humor, and to express feelings. The results show that women use emoticons more often to show humor, while men use emoticons for sarcasm. Other studies explain that women use more emoticons to express emotions, show solidarity, support and affirm positive feeling (Wolf, 2000).

Nevertheless, nonverbal cues such as voice intonation and performance are still not obtained in the current emoticon symbol. This is what distinguishes face-to-face communication from mediated interpersonal communication. In face-to-face communication, nonverbal symbols spontaneously accompany verbal symbols delivered by individuals involved in the communication process. But in interpersonal communication mediated, nonverbal cues are not spontaneous but complement verbal cues delivered in social media.

Basically, these nonverbal cues can be obtained through symbols in the form of text or images contained in the CMC. According to Soranaka and Matsushita (2012), emoticons that exist today replace the four parts in non-verbal cues, namely the facial expressions that can be seen in the emoticon image smiling (:), laughing (-), angry (2) and crying (i) sad (Soranaka \& Matsuhita, 2012). The second group is the gesture indicated by the hand symbol pointing $\mathbb{m}^{-1} \hat{y} \in$. The third group of body language is shown with pictures of dancing people $q^{9}$ behavior is shown with pictures of various forms of eyes ranging from glaring (20) (20) or narrowing $(O)$. Of the four sections, from nonverbal cues attached to an individual's self, it can be said that the symbols in the emoticon are to replace kinetic nonverbal symbols. At the same time, the digital vocal code includes textual elements related to digital sounds.

Second, the emoticon functions as a regulator of speech. The emoticons are often used by netizens to avoid debate in discussions on social media. This function is like a nonverbal signal function in face-to-face communication, often used to regulate verbal behavior. This research data illustrate that emoticons are not only for expressing their feelings but also that emoticons are used by netizens to avoid conflicts with fellow netizens. As revealed by the following informant: "... or use a smile emoticon for some 
people who usually ask to argue so that they don't get longer, in the sense of ending the discussion."

This phenomenon illustrates that emoticons have the same role as nonverbal cues in face-to-face communication, one of which is to regulate the flow of messages. Among them, smile (2) emoticons are used to not prolong debates or differences of opinion, including hand symbol emoticons (thumbs 道 or sorry potential to reduce negative responses that arise in internet-mediated communication (Thompson \& Filik, 2016). Although in CMC there is no eye gaze or gesture commonly used to organize messages, the emoticon symbol can also be used by netizens in managing messages in the sense of when the message must start or end. In face-to-face communication, nonverbal cues, besides functioning as a message regulator, also function as message controllers and modify messages (Kiesler et al., 1984). In fact, the nonverbal signaling functions in face-to-face communication are also illustrated in emoticons in mediated interpersonal communication. This can be seen from the statements of informants about how they use emoticons in social media.

The statement also illustrates that women tend to avoid open conflicts that can occur in the process of interpersonal communication. In order to avoid open conflict, informants use emoticons as a way to neutralize the communication process. This is in line with stereotypes about women in social relations where they tend to maintain harmonization and avoid conflict (Fischer, 2011). Therefore, the actual emotion used in messages on social media does not necessarily accurately reflect the feelings of the author of the message, as the results of previous studies show that the use of positive and negative emotions is not always the same as the emotional condition of the author (Brito et al., 2019).

Thus it can be said that the emoticons used by netizens in conversation on social networking media basically have replaced nonverbal sign functions as Burgoon writes that the emoticons used in CMC are expected to have the same effect as nonverbal cues in face-to-face communication (Burgoon et al., 1996). As with nonverbal cues in face-toface communication that can function to emphasize, substitute, repeat or contradict the message delivered, emoticons also have these functions.

Is the Emoticon Reconstructing a Nonverbal Symbol?

In this study, the study of the Bening Society community, which has a female affiliation, also found frequent expressions of smile (2) and laughter $\theta$ used when communicating through Facebook. In addition to maintaining good relations among fellow members, the use of emoticons is also intended to facilitate social acceptance for Bening members considering they have not known each other well. In addition to emoticons in the form of facial expressions, the other emoticon symbol that is widely

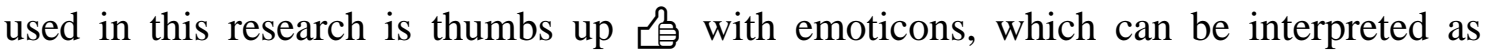
positive. This illustrates that emoticons are used as a form of expression of support to other parties.

The research data show that not all emoticons are used by netizens; although emoticons provide them with many symbols or symbols, many are not used by Bening Society members. The research data show that the unused symbols are less familiar ( (2) symbol, so that she does not understand the condition or symbol used to support what verbal or what kind of message is. As the second informant said, they did not understand the meaning of all emoticon symbols because they were too general. 
This condition occurs because not all Facebook users have the same skills and abilities. Therefore, Facebook users prefer to use cues or symbols that are already widely used by others, so Facebook users are not afraid of wrong use of emoticons. This fact illustrates that emoticons can also provide additional functions, namely as social information outside of the verbal message, as is also common in nonverbal cues on faceto-face communication. This means that the use of emoticons can improve the effectiveness of communication because the existence of emoticons is basically as a loss of nonverbal cues in CMC.

Thus netizens feel that it is not difficult to conduct interpersonal communication mediated through social media even though they do not meet physically and cannot catch some nonverbal cues as in face-to-face communication. As explained in the CuesFiltered-In perspective, basically, internet users can adapt well in CMC even though nonverbal cues are not found, such as in face-to-face communication (Riordan, 2011). This can be seen in the results of the study that Facebook users feel that they are not awkward in building relationships and communicating even though they have not known each other before. The establishment of strong bonds between netizens (members of the Bening Society community) is one proof that the absence of nonverbal cues such as performance, voice intonation, eye gaze--which is often the basis for an individual's assessment of whether communication will continue or not--does not prevent netizens from building social relationships.

\section{Discussion}

An emoticon is a symbol that is popular today among netizens. Emoticons use is expected to facilitate netizens in delivering messages, especially those related to feelings. Not only that, but the results of this study also illustrate how emoticons seem to have replaced the function of nonverbal symbols. The research data above also reveal that emoticons are not always interpreted and used by netizens in accordance with the characters or images in the emoticon. Every individual social media user has "freedom" in interpreting and using emoticons. According to Park and Roberts, emoticons are sociocultural products, and the meaning of emoticons can be influenced by the identity and character of individual users (Parks \& Roberts, 2013). Therefore the use of emoticons is very dependent on the conditions and conditions when mediated interpersonal communication takes place.

This fact is also interesting in terms of the use of emoticons in mediated interpersonal communication. Emoticons are positioned as a 'substitute' signal nonverbal but in their use they can be interpreted by individuals involved in mediated communication; this is very different from nonverbal cues. Given that face-to-face communication using nonverbal cues is always followed by verbal cues, the meaning of verbal cues depends on the nonverbal cues that accompany them. This is different with emoticons, which, in their use, do not always have to depend on text messages. Emoticons can be used separately with text messages. The use of the emoticon 'smile' (-) as done by the first informant is not accompanied by verbal sentences, but the meaning of the communicant can be accepted.

If in face-to-face communication, nonverbal symbols have various forms used to support verbal symbols, this does not happen with emoticons. Although various forms of emoticons are available with various images, most netizens, especially on Facebook's social media networks, use emoticons with laugh expressions. Likewise, with the 
observations of researchers about the use of emoticons, especially on the Bening Society community's Facebook page, it was found that the emoticon symbols most often used by members of Bening are in the form of facial expressions. Namely, smile $(\mathcal{)}$, laugh $(-)$, love $\odot$, and sadness 2 (crying). This is in line with previous research conducted by Wolf (2000), which concluded that, in women's groups on the internet, smiley emoticons were used more as a sign of solidarity and humor (Wolf, 2000). Other studies also mentioned that women internet users more often use emoticons to express their feelings (Hwang, 2014).

The results of other studies on Facebook showed that most Facebook users used emoticons with laugh expressions where $51 \%$ expressed it by writing "haha," $33.7 \%$ described it with laughing emoticons, $13.1 \%$ by writing it down, and $1.9 \%$ with writing "LOL" (Bickell, 2014). Furthermore, Bickell stated that, although the number of emoticons is increasing, most netizens when using social media only use a few, and the most chosen are laughing expressions.

In face-to-face communication, women tend to be more expressive in expressing their needs; this expression reflected in their facial expressions. It seems that this is also done by women when communicating through social media. Because of that, women tend to use emoticons more often with facial expressions than other emoticons. The results of research conducted by Hecht concluded that women smile more than men when they use face-to-face communication (Fischer, 2011). This is because women always want to maintain a harmonious relationship

The existence of limitations in emoticons or other nonverbal symbols in mediated interpersonal communication does not reduce the reality of not reducing netizens' desire to use emoticons and other symbols in the process of mediated interpersonal communication. The research data above show that netizens often use emoticons to show their feelings and to manage the flow of communication. However, not all symbols in emoticons are used by netizens. This is interesting because netizens feel they can represent their feelings or emotional states only through certain symbols. And the symbol is chosen because it is already 'familiar' or commonly used by many netizens.

In the context of interpersonal communication mediated, netizens no longer need nonverbal cues that vary in form. Given the many nonverbal cues that are born and constructed based on the culture of each region, according to Mulyana (Mulyana, 2017) nonverbal cues are not universal but are culturally bound. In culture, there may be nonverbal language variations. In mediated interpersonal communication, a variety of nonverbal cues are no longer found. Everything becomes the same in expressions of when netizens are happy, cheerful, sad, or angry, whereas in face-to-face communication, these expressions will vary from nonverbal signals because each culture will have a different way of expressing something. The fact is, in cyberspace, all netizens actually openly accept new symbols that are homogeneous. This means that the new symbol is very uniform in shape--like emoticons--coming from a new culture, that is a culture created by cyberspace.

Homogeneity occurs, as many have been described above, because of the absence of nonverbal cues in mediated interpersonal communication; so as to facilitate the process of interdependent communication, individuals try to adapt to cyberspace. Adaptation is by creating verbal sentences, punctuation, thickening or repeating messages as a form of emphasis, and creating emoticons that can describe nonverbal cues such as face-to-face communication. The process of wanting to adapt it finally gave rise to the homogenization of CMC users. Homogenization occurs in the use of verbal symbols such as to describe 
laughter, so many people write "haha" or "hehe," which is then interpreted the same. Likewise, with symbols or symbols in emoticons, all forms of facial expression have something in common. As regard limited symbols or images in emoticons, in the literature it is said that emoticons are considered as a substitute sign for the tone of voice, facial expression, and body language, eventually 'forcing' netizens to use these symbols in the process of mediated communication.

However, in face-to-face communication, the meaning of verbal messages is very dependent on nonverbal cues that accompany the verbal message. Besides that, every culture will also have different cues. As mentioned in one of the nonverbal communication characteristics, namely that nonverbal communication is bound to culture. This means that each culture will give birth to different nonverbal cues (Budyatna \& Ganiem, 2011). Gestures and body movements have different meanings in all cultures. Therefore, if a person does not understand a particular culture, it is certain that they will have difficulty communicating. But in social media, social media users have uniform (nonverbal) cues that are no longer influenced by the message text or the culture of the individual. In the sense that emoticons that are considered as non-verbal symbols in mediated interpersonal communication will be interpreted by netizens even though netizens actually come from different places with different cultures.

Thus it can be said that the use of communication symbols used in social media is basically not as substitute nonverbal but rather as a simplification in the process of communicating, especially mediated interpersonal communication. The author considers that the simplification of nonverbal symbols in mediated interpersonal communication will gradually eliminate local culture so as to make it easier for others to master the community in a particular area. Thus it can be said here that, in the cyber world, the society is very homogeneous, so it is not surprising that the cyber society has similar attitudes and behaviors.

This study has limitations, namely it is on one social media platform, namely Facebook, and has not explored other social media platforms such as Instagram or Twitter which are widely used as a medium of communication for netizens today. In addition, the weakness in this research is the use of symbols or emoticons in the female community, so that the description of how nonverbal symbols in mediated interpersonal communication is not yet complete with text or symbols in the form of emoticons.

\section{Conclusion}

Interpersonal communication mediating the existence of emoticons actually has been able to replace the function of nonverbal cues, especially in representing feelings or emotions and regulating the flow of messages. As a result, many things must be reconstructed or conceptualized related to nonverbal cues due to the increasing frequency of individuals conducting mediated interpersonal communication, including reviewing how nonverbal symbols or symbols, including emoticons, have given rise to a homogeneous culture in all cyberspace, whereby they must have various forms of nonverbal cues that are tied to their culture. The research results recommend examining emoticons and nonverbal communication associated with local culture in a cyber society. 


\section{Conflict of Interest}

We certify that there is no conflict of interest with any financial, personal, or other relationships with other people or organization related to the material discussed in the manuscript.

\section{Acknowledgements}

The author would like to thank LPPM Universitas Pembangunan Nasional "Veteran" Jawa Timur for giving me the opportunity to continue this research.

\section{References}

Adnan, H. M., \& Mavi, S. R. (2015). Facebook satisfaction, life satisfaction: Malaysian undergraduate experience. Jurnal Komunikasi: Malaysian Journal of Communication, 31(2), 649-671. https://doi.org/10.17576/jkmjc-2015-3102-37

Aldunate, N., \& González-Ibáñez, R. (2017). An integrated review of emoticons in computer-mediated communication. Frontiers in Psychology, 7, 1-6. https://doi.org/10.3389/fpsyg.2016.02061

Amichai-Hamburger, Y., \& Vinitzky, G. (2010). Social network use and personality. Computers in Human Behavior, 26(6), 1289-1295. https://doi.org/10.1016/j.chb.2010.03.018

Bickell, K. (2014). Are Emoticons A Woman Thing? Herizons, Academic Search Complete, 27(4), 16-19.

Bowler, G., \& Bowler Jr, G. M. (2010). Netnography: A method specifically designed to study cultures and communities online. The Qualitative Report, 15(5), 1270-1275.

Brito, P. Q., Torres, S., \& Fernandes, J. (2019). What Kind of Emotions do Emoticons Communicate? Asia Pasific Journal of Marketing and Logistics.

Budyatna, M., \& Ganiem, M. L. (2011). Teori Komunikasi Antar Pribadi. Kencana Prenada Media.

Burgoon, J. K., Buller, D. B., \& Woodall, W. G. (1996). Nonverbal Communication: The Unspoken Dialogue (Second Edi). McGraw Hill.

Craig, E. \& Wright, B., K. (2012). Computer-Mediated Relational Development and Maintenance on Facebook. Communication Research Reports, 29(2), 119-129.

Derks, D., Bos, A. E. R., \& Von Grumbkow, J. (2008). Emoticons in computer-mediated communication: Social motives and social context. Cyberpsychology and Behavior, 11(1), 99-101. https://doi.org/10.1089/cpb.2007.9926

Dresner, E., \& Herring, S. C. (2010). Functions of the nonverbal in CMC: Emoticons and illocutionary force. Communication Theory, 20(3), 249-268. https://doi.org/https://doi.org/10.1111/j.1468-2885.2010.01362.x

Ellison, N. B., Gray, R., Lampe, C., \& Fiore, A. T. (2014). Social capital and resource requests on Facebook. New Media \& Society, 16, 1104-1121.

Fischer, A. (2011). Gendered Social Interaction in Face-to-Face and Computer-Mediated Communication. In K. A. \& K. C. Nicole (Ed.), Face-to-Face Communication over the Internet: Emotions in a Web of Culture, Language and Technology. Cambridge University Press.

Hogenboom, A., Bal, D., Frasincar, F., Bal, M., De Jong, F., \& Kaymak, U. (2013). Exploiting emoticons in sentiment analysis. Proceedings of the ACM Symposium on Applied Computing, 703-710. https://doi.org/10.1145/2480362.2480498

Hu, Yue., Zhao, Jichang, \& Wu, J. (2016). Emoticon-Based Ambivalent Expression: A Hidden Indicator for Unusual Behaviors in Weibo. Plos One. 
Huffaker, D. A., \& Calvert, S. L. (2017). Gender, Identity, and Language Use in Teenage Blogs. Journal of Computer-Mediated Communication, 10(2). https://doi.org/10.1111/j.1083-6101.2005.tb00238.x

Hunt, D., Atkin, D., \& Krishnan, A. (2012). The Influence of Computer-Mediated Communication Apprehension on Motives for Facebook Use. Journal of Broadcasting and Electronic Media, 56(2), 187-202. https://doi.org/10.1080/08838151.2012.678717

Huynh, Kim-Phong, Lim, Si-Wei, \& Skoric, M. M. (2013). Stepping out of the Magic Circle: Regulation of Play/Life Boundary in MMO-Mediated Romantic Relationship. Journal of Computer-Mediated Communication, 18(3), 251-264. https://doi.org/https://doi.org/10.1111/jcc4.12011

Hwang, H. S. (2014). Gender Differences in Emoticon Use on Mobile Text Messaging: Evidence from a Korean Sample. International Journal of Journalism \& Mass Communication, 1(1), 1-4. https://doi.org/10.15344/2349-2635/2014/107

Indriani, S. S., \& Prasanti, D. (2019). Understanding Multiculturalism in a Family on Whatsapp Group in the Disruption Era. Jurnal The Messenger, 11(2), 209. https://doi.org/10.26623/themessenger.v11i2.1267

Kasanah, U. (2011). Memahami Keterbukaan Komunikasi Antar Pribadi Dalam Percakapan Online. In Jurnal The Messenger (Vol. 3, Issue 1, p. 33). https://doi.org/10.26623/themessenger.v3i1.194

Kaye, L. K., Malone, S. A., \& Wall, H. J. (2017). Emojis: Insights, Affordances, and Possibilities for Psychological Science. In Trends in Cognitive Sciences (Vol. 21, Issue 2, pp. 66-68). https://doi.org/10.1016/j.tics.2016.10.007

Kiesler, S., Siegel, J., \& McGuire, T. W. (1984). Social psychological aspects of computer-mediated communication. American Psychologist, 39(10), 1123-1134. https://doi.org/10.1037/0003-066X.39.10.1123

Konijn, E. A., Utz, S., Tanis, M., \& Barnes, S. B. (2008). Mediated interpersonal communication. In Mediated Interpersonal Communication. https://doi.org/10.4324/9780203926864

Kozinets, R. V. (2015). Netnography. Sage.

Krishnan, A., \& Hunt, D. S. (2019). TTYL :-) ... Nonverbal cues and perceptions of personality and homophily in synchronous mediated communication. Information, Communication and Society, 24(1), 85-101. https://doi.org/10.1080/1369118X.2019.1635183

Liu, L., Liu, X., Cheng, S., \& Li, K. (2018). Research on Relationship between the Comprehension an Usage of Emoticon. International Join Conference on Information, Media and Engineering, 55-60.

Marengo, D., Giannotta, F., \& Settanni, M. (2017). Assessing personality using emoji: An exploratory study. Personality and Individual Differences, 112, 74-78. https://doi.org/https://doi.org/10.1016/j.paid.2017.02.037

Mulyadi, U., \& Fitriana, L. (2018). Hashtag (\#) as Message Identity in Virtual Community. Jurnal The Messenger, 10(1), 44. https://doi.org/10.26623/themessenger.v10i1.671

Mulyana, D. (2017). Ilmu Komunikasi: Suatu Pengantar (21st ed.). Remaja Rosdakarya.

Parks, M. R., \& Roberts, L. D. (2013). Making Moosic: The Development of Personal Relationships Online and a comparison to Their Offline Counterparts. Journal of Social and Personal Relationship, 15(4), 517-537. 
Pearce, K. E., Barta, K., \& Fesenmaier, M. A. (2015). The affordances of social networking sites for relational maintenance in a distrustful society: The case of Azerbaijan. Social Media + Society, 1(2).

Remland, M. (2017). Nonverbal Communication in Organizations. The International Encyclopedia of Organizational Communication.

Riordan, M. A. (2011). The Use of Verbal and Nonverbal Cues in Computer-MediatedCommunication: When and Why? [University of Memphis]. https://digitalcommons.memphis.edu/etd/158

Sait, S. M., \& Sattar, K. A. (2018). Empirical study on use of online social networking sites in the Kingdom of Saudi Arabia. Jurnal Komunikasi: Malaysian Journal of Communication, 34(4), 93-112. https://doi.org/10.17576/JKMJC-2018-3404-06

Skovholt, K., Grønning, A., \& Kankaanranta, A. (2014). The communicative functions of emoticons in workplace e-mails::-). Journal of Computer-Mediated Communication, 19(4), 780-797. https://doi.org/10.1111/jcc4.12063

Soranaka, K., \& Matsuhita, M. (2012). Relationship Between Emotional Words and Emoticons in Tweets. 2012 Conference on Technologies and Applications of Artificial Intelligence, 262-265. https://doi.org/10.1109/TAAI.2012.30.

Stafford, L., \& Hillyer, J. D. (2012). Information and communication technologies in personal relationships. Review of Communication, 12, 290-312. https://doi.org/:10.1080/15358593.2012.685951

Stieger, S., Burger, C., Bohn, M., \& Voracek, M. (2013). Who Commits Virtual Identity Suicide? Differences in Privacy Concerns, Internet Addiction, and Personality Between Facebook Users and Quitters. Cyberpsychology, Behavior, and Social Networking, 16(9), 629-634. https://doi.org/10.1089/cyber.2012.0323

Thompson, D., \& Filik, R. (2016). Sarcasm in Written Communication: Emoticons are Efficient Markers of Intention. Journal of Computer-Mediated Communication, 21(2), 105-120. https://doi.org/10.1111/jcc4.12156

Thompson, D., Mackenzie, I. G., Leuthold, H., \& Filik, R. (2016). Emotional Responses to irony and emoticons in written language: evidence from EDA and Facial EMG. Psychophysiology, 53, 1054-1062.

Tov, W. (2015). Sharing feelings online: studying emotional well-being via automated $\begin{array}{lllll}\text { text analysis of Facebook } & \text { 6(July), }\end{array}$ https://doi.org/10.3389/fpsyg.2015.01045

Tseng, T. H., \& Hsieh, S. H. (2017). Determinants of emoticon usage in mobile instant messaging: a construal level theory perspective. Behavior and Information Technology, 38(3), 289-301.

Urabe, Y., Rzepka, R., \& Araki, K. (2013). Emoticon Recommendation system for effective communication. ACM Transactions on Internet Technology, 1460-1461.

Veil, S. R., Buehner, T., \& Palenchar, M. J. (2011). A Work-In-Process Literature Review: Incorporating Social Media in Risk and Crisis Communication. Journal of Contingencies and Crisis Management, 19(2), 110-122. https://doi.org/10.1111/j.1468-5973.2011.00639.x

Walther, J. B. (1996). Computer-mediated communication: impersonal, interpersonal, and hyperpersonal interaction. Communication Research Reports.

Wolf, A. (2000). Emotional Expression online: Gender Differences in Emotikon Use. CyberPsychology \& Behavior, 3, 827-833. 